Central Washington University

ScholarWorks@CWU

All Faculty Scholarship for the College of the Sciences

College of the Sciences

6-2011

Asynchronous Use of Engineering (Materials) Education Videos

Craig Johnson

Arthur D. Morken

Follow this and additional works at: https://digitalcommons.cwu.edu/cotsfac

Part of the Educational Technology Commons, Engineering Education Commons, Instructional Media Design Commons, and the Online and Distance Education Commons 


\section{AC 2011-1144: ASYNCHRONOUS USE OF ENGINEERING (MATERI- ALS) EDUCATION VIDEOS}

\section{Craig Johnson, Central Washington University}

Craig Johnson, Ph.D., P.E., is a professor at Central Washington University teaching materials courses and managing their foundry. He coordinates both the Mechanical Engineering Technology and Industrial Technology Cast Metals programs.

\section{Arthur D. Morken, Central Washington University}

Mr. Morken is a Graduate Teaching Assistant at Central Washington University. With more than ten years experience as an educator Mr. Morken has been immersed in educational technology relevant issues. Due to the escalating demands placed on instructors he is constantly looking for more efficient methods of student interaction for the improvement of student learning through the aid of technological tools. 


\title{
Asynchronous Use of Engineering (Materials) Education Videos
}

\begin{abstract}
Engineering education delivery is dynamic and increasingly asynchronous. An observation that students had very different levels of knowledge and skills as they progressed through our programs, led the authors to use audio/visual media as a leveling intervention. In this effort the authors collected data to determine if audio/visual media can be used to increase performance in the development of a program related task and guide students to higher levels of learning on Blooms Taxonomy through the development of student created learning aids.
\end{abstract}

One specific need was reflected in the disparate skills of our majority component of 'transfer' students in our programs. Through informal observations the authors realized students simply did not have familiarity with the equipment at our facility (as opposed to their previous experiences elsewhere). In this study, the authors target one simple skill relevant to resistance welding that could be used as an introduction to metallurgy concepts (welding band saw blades). This student project was used not only to provide students with a practical skill for their applications toolbox but additionally as a way to construct departmental teaching aids for other processes as students synthesize learning and create their own media presentations. The eventual goal of having procedural information readily available for students unfamiliar with specific equipment needed for interdisciplinary projects involving our programs.

There were many interesting aspects to this effort. The first involves the creation of audio/visual content because of the many forms (resolution), lengths (venues), and content (audience). The second aspect of interest was the effectiveness of the effort. This was primarily measured through the use of two control groups and the outcomes of the assigned project. Finally, the continuous process improvement information that lead beyond the original intent of creating a single video to a more discrete and relevant approach to doing so guided by student feedback.

\section{Introduction}

Much time has been spent teaching our students safe and efficient operations in our labs. A particular scenario was identified concerning the operation of our machine shop equipment, such as our band saws. Freshman that have completed our introductory machining course are aware of band saw use (appropriate metals, dimensions and speeds), but many have not repaired a broken blade. Also, transfer students (comprising the majority of our graduating seniors) are typically not trained in the use and maintenance of our band saws.

In an attempt to decrease the amount of maintenance and instruction time required by our lone staff technologist, an idea was developed to create videos that addressed these needed skills, concepts and issues. The videos might also be used to supplement introductory course content (and other content as needed). This particular video was also used to introduce the concepts of resistance welding and basic metallurgy. So our intention is that this video be used by the students to improve their knowledge of the content (repairing band saw blades), as well as to improve higher cognitive skills (e.g. Bloom's Taxonomy ${ }^{1}$ ) such as 'demonstration or applying' 
and 'designing or creating' a solution to fix repair issues. Students progress through the levels of Bloom's Taxonomy and Bloom's Revised Taxonomy (see Figure 1 below) in an effort to achieve mastery.

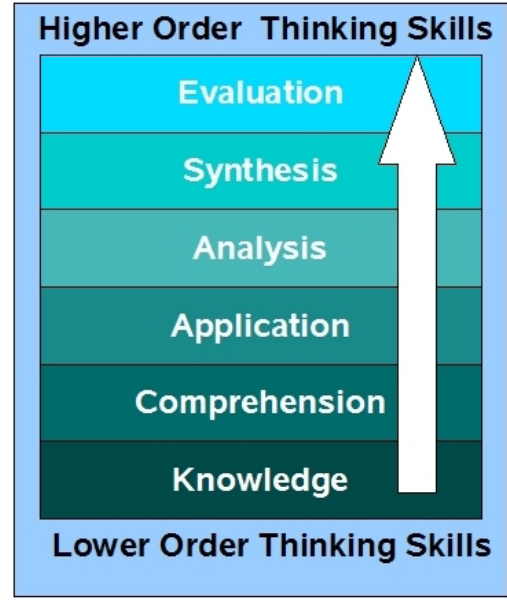

Drawing 1: Bloom's Taxonomy Drawing by $A$ Churches

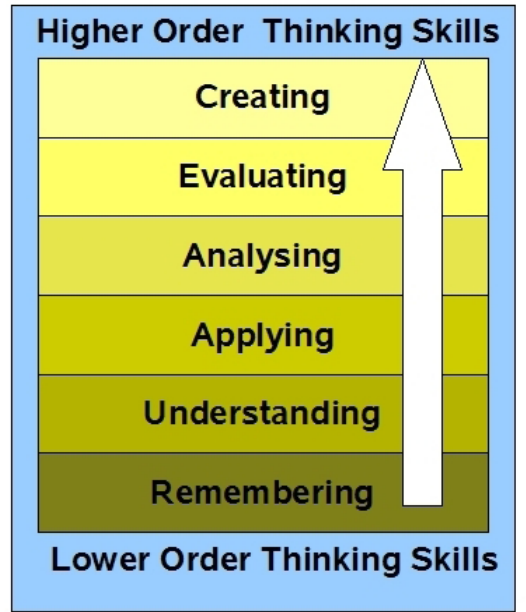

Drawing 2: Bloom's Revised Taxonomy

Drawing by $A$ Churches

Figure 1, Blooms original and revised taxonomy graphics ${ }^{2}$

We looked for available and relevant videos. There was no such material evident within the school, but searches did turn up some similar material such as those from Georgia Tech (Jonathon Colton) on NDSL - National Direct Science Library ${ }^{3}$ (general search for 'resistance welding') though access to this material has recently been removed from public. There may be related commercial videos, but we've not found them for our specific needs. One video that was found after we started this work was a procedural type by 'APmachinist' on YouTube ${ }^{4}$. However, this does not have the concept background or assessment components that we were interested in specific to our situation.

It is also not obvious that students will use these videos. For a video to make any substantive, positive impact on student's abilities, they have to be viewed. Educators can refer to their own experiences and reflect on how many students regularly 'use' the Internet to access appropriate information. This educator recently graded an assignment in which less than half the class made the effort to access information easily found on-line.

The scope of this work is focused on both creating and documenting content (e.g. videos and Power Points) and assessing their effectiveness in our academic environment. We chose to embed access to the videos in the course curricula to circumvent some issues of 'student motivation' and require participation through a graded assignment.

\section{Methodology}

We focused our skill component on the specific task of maintaining band saw blades. It is introduced as an example of resistance welding in part because it is 'simple' (a low number of process parameters) and has limited skill input diversity. This was also a way to discuss how 
metallurgical microstructure is affected by welding and heat-treating. For example, students compare 'sparks' from mild steel vs. sparks from the blade steel, flexural strength, and hardness testing in relation to annealing. It's cost-effective and relatively short in duration. Other welding applications have many additional variables. In this resistance weld procedure, many weld parameters can be fixed (e.g. temperature, time, and pressure), so we can concentrate on how the annealing process affects its properties.

We assess the student's abilities to demonstrate a successful weld (e.g. weld and subsequent profile test and bend test). We also evaluate hardness and tensile properties in order to create some instructional and discussion material. After viewing, students were tested on knowledge (e.g. procedural) and design (e.g. changing process parameters to suit varying material and/or conditions). Students progressed from knowledge (process sequence and terminology) to comprehension (safe use of the process) and application (relating the knowledge to more complex welding procedures) as they prepared their own samples. Through the welding process students had the opportunity to reflect on the process in a written assignment. This assignment not only allowed for analysis of what went well in the process but the opportunity to hypothesis why certain samples had poor visual characteristics.

Instruction was considered effective if the student was able to achieve Rockwell hardness relatively close to that of the base material in addition to a sample free of visual defects. The student's written assignment was a valuable tool, through the collection of student's comments, suggestions for improvements and pinpointing errors or omissions in the process additional clarifications were and are being made. Through this process of review students contributed not only to making the teaching aid better but participated in the decision-making process of what their assigned project should look like. In an effort to reach the highest levels of learning students evaluated not only what they learned but the process by which they learned. Through this evaluation students where able to synthesize the entire process and create a similar experience for other course and machine processes. Using available educational technology in all learning environments helps engage the "Digital Natives" information through structured academic courses. William Arthur Ward is contributed with saying, "The mediocre teacher tells. The good teacher explains. The superior teacher demonstrates. The great teacher inspires ${ }^{5}$." Through the telling, explaining, and demonstrating of material it is our goal to inspire others to passionately share what they have learned, thus a full circle of learning is revolved.

The videos were created in 2010-2011, and deployed in 2011. Classes of fifteen students were involved in this research during the fall of 2010 and winter of 2011. Bloom's Digital Taxonomy as presented by Andrew Churches, is an excellent resource for understanding media in various venues of learning. Figure 2 below is useful in learning about the relevant skills and learning process and how the creation of a student video reaches higher levels of learning. 


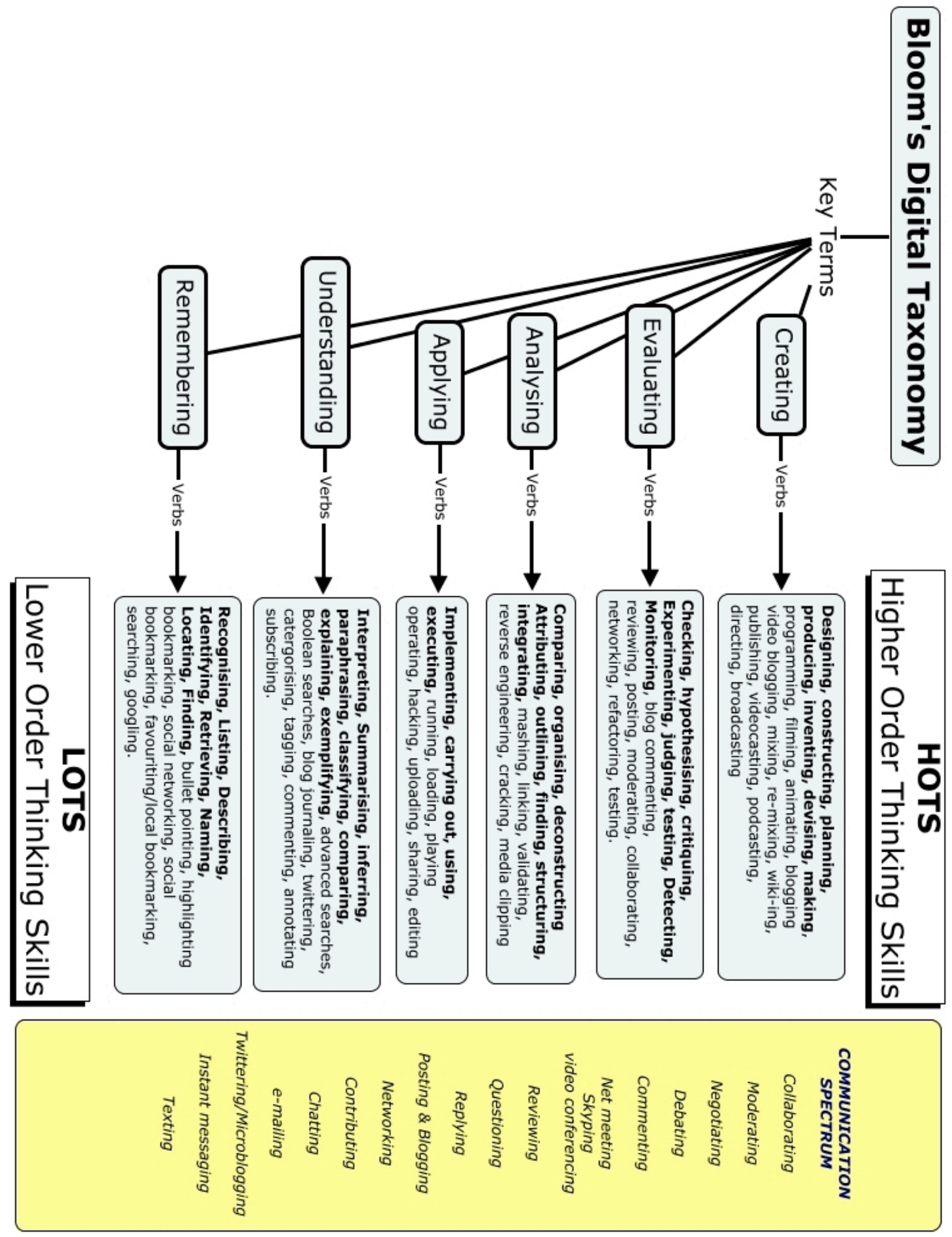

Figure 2 Blooms Digital Taxonomy ${ }^{3}$

D
$\mathscr{O}$
$\mathbb{0}$
$N$
$N$
$N$
$N$
$N$
$\sim$ 


\section{Video Issues}

"The devices that the teachers use to help them convey their meaning to students are many and varied. They can range from a diagram drawn in the sand with a stick to an expensive language laboratory or closed circuit television service. Used sensibly, teaching aids can be of value to any teacher, and even adding an extra dimension to his teaching... What should be the basic tools of the teacher's craft have often been obscured in a fog of incomprehension."

Content: Raw video footage was created with multiple intentions. Short versions of simple (low Bloom's Taxonomy) 'operations used for the presentation of knowledge,' but longer versions were also intended for creation that would support much more depth into the weld process, testing procedures, and metallurgical characterization.

Length (venues): We could have simply filmed the operation (or process) and been done in a half hour. But we chose to make many 'takes' in order to get both the operational content and the specific terms for our machine, as well as allow for the inclusion of support knowledge and concepts. It's one thing to say that you hold down the 'anneal' button until 'it glows'. It's another thing to understand the original microstructure, and how both the resistance weld and the post-weld anneal affect the microstructure (and even better to predict the resulting properties). We also were able to get enough raw material to eventually make different 'formats' (e.g. short vs. longer, HD vs. NTSC) for different venues (we could create different footage videos and perhaps avoid some copyright issues).

Resolution: We did record the video on a 'high capacity SD' card, but it could only be read on a few of our newer machines. The data has since been converted to other formats. For our purposes, an HD version was created but not essential for use within our university Blackboard system.

Video Process Issues: We took the video with a compact camera. This was straightforward, but did constrain the ability to create certain effects. We downloaded the video to an older computer, which slowed the process a great deal (e.g. it took hours). We recommend the fastest computer you can get with compatible formats for all programs involved. We chose to make the videos simple and strait forward without graphics or other time-intensive features. The editing and titling of information took the majority of time outside of student interaction.

\section{Results: Education Assessment}

We used the video in our curricula two ways. After an initial lecture in the winter to two groups, one student group viewed the video after performing the welds, and a second group looked at the PowerPoint after completing their welds. This was accomplished during one of the typical 3hour class periods. Both groups had additional opportunities for visual, auditory, and kinesthetic learning. This opportunity was used to collect feed back on the media in addition to discussion of the students' requirement of creating their own media. These added opportunities should have reinforced the material for all students; multiple modalities can assist students in increasing the 
comprehension of knowledge. In teaching, it is often related that, methods used should be comfortable to the instructor and effective for the student. In increasing technological times this may stretch many beyond their normal comfort zones in an effort to make engaging and relevant learning experiences for all students. Using this example video relevant to course content was not only for instructional purposes on this topic but also segway into student development of additional resources. As we emerge in the Web 2.0 world, it is with caution and holding onto the static and controllable environments of earlier experiences and more traditional teaching methods. Making a transition from the teacher controlled classroom towards a community of learners needs to be coupled with responsible dissemination of information that can be verified through primary sources and factual documentation. For these reasons student created content must be examined and edited if needed before releasing it for general viewing. As educators the increasing challenges of moving from the industrialized to the technological society include exponential growth and the opportunity for misinformation.

Looking at collected data, the second group performed the welding procedure better than the first group (see Table 1 below). Better, more successful welds indicated that students were better prepared to construct a stronger more appropriate weld. Additionally each group performed better in comprehension. They were able to analyze and understand what they did wrong and how to fix it. For example, these students were able to predict changes in weld behavior based on changes in weld parameters. Confucius is quoted, "I hear and I forget, I see and I remember, I do and I understand. ", This informal collection of information in a small class setting leads one to believe that when students are given the basic knowledge needed to proceed safely they will comprehend more through the discovery of relevant variables in pursuit of a given result. Validation of these variables comes through replication, class discussion, collaboration, and applications to other relevant course projects. This analysis on their part is important to foster the needed problem solving skills of an adapting and forward thinking generation. This analysis transfers as students begin work on their individual problems and creating videos for additional course and departmental processes.

We assessed the students and the results indicated that the video and PowerPoint enhanced the student's ability to use appropriate terminology in describing the procedure, as well as explaining the repercussions of changes in weld parameters.

\section{Results: Video Interaction}

The following table indicates a mean of $83 \mathrm{ksi}$ in tensile testing of samples. This was done in a class setting after students completed initial samples. The lecture portion was done in conjunction with a demonstration, 15 students huddled around one machine. Not all students could see and interact appropriately in this setting.

\begin{tabular}{lrlrll} 
& \multicolumn{3}{c}{ Width } & & Depth \\
Name & Force (pounds) & (inches & & (inches) & \multicolumn{1}{l}{ psi } \\
Base Material & $\mathbf{1 7 5 5}$ & $\mathbf{0 . 3 8 2 5}$ & $\mathbf{0 . 0 2 5}$ & $\mathbf{1 8 3 5 2 9 . 4}$ \\
Student 1 & 1470 & 0.405 & 0.026 & 139601.1 \\
Student 2 & 990 & 0.3225 & 0.025 & 122790.7 \\
Student 3 & 1100 & 0.3675 & 0.0255 & 117380.3
\end{tabular}




$\begin{array}{lrrrr}\text { Student 4 } & 1030 & 0.362 & 0.0255 & 111580.5 \\ \text { Student 5 } & 890 & 0.361 & 0.0245 & 100627.5 \\ \text { Student 6 } & 775 & 0.4 & 0.0235 & 82446.81 \\ \text { Student 7 } & 875 & 0.3805 & 0.029 & 79296.75 \\ \text { Student 8 } & 660 & 0.3575 & 0.025 & 73846.15 \\ \text { Student 9 } & 765 & 0.419 & 0.026 & 70222.14 \\ \text { Student 10 } & 800 & 0.3955 & 0.029 & 69750.21 \\ \text { Student 11 } & 580 & 0.3625 & 0.0245 & 65306.12 \\ \text { Student 12 } & 600 & 0.3835 & 0.025 & 62581.49 \\ \text { Student 13 } & 600 & 0.39 & 0.0255 & 60331.83 \\ \text { Student 14 } & 25 & 0.423 & 0.0245 & 2412.312 \\ & & & & 82726.71\end{array}$

As presented in Table 2, below, data shows an increase in the overall psi. An increased mastery of subject mater is reflected through the visual inspection and data collected in the class. This second set of data reflects not only the additional instructional time but how it was presented. Increased strength of welds was greatest by those students using the Power Point, this may in fact be a reflection of their comments, "I could take the hardcopy with me to the lab."

\begin{tabular}{|c|c|c|c|c|c|}
\hline Name & Pounds & Width & Thickness & PSI & \\
\hline Base Material & 1755 & 0.3825 & 0.025 & 183529.4 & \\
\hline Student 21 & 1185 & 0.3815 & 0.0205 & 151520 & \\
\hline Student 22 & 1100 & 0.3785 & 0.0225 & 129164.8 & \\
\hline Student 23 & 1205 & 0.339 & 0.028 & 126949 & \\
\hline Student 24 & 1385 & 0.397 & 0.028 & 124595.2 & \\
\hline Student 25 & 1080 & 0.3685 & 0.025 & 117232 & \\
\hline Student 26 & 1180 & 0.408 & 0.025 & 115686.3 & \\
\hline Student 27 & 870 & 0.404 & 0.0205 & 105047.1 & \\
\hline Student 28 & 1075 & 0.3965 & 0.0265 & 102310.3 & \\
\hline Student 29 & 785 & 0.38 & 0.0225 & 91812.87 & \\
\hline Student 30 & 805 & 0.365 & 0.025 & 88219.18 & \\
\hline Student 31 & 620 & 0.4045 & 0.024 & 63864.85 & \\
\hline Student 32 & 845 & 0.411 & 0.033 & 62301.85 & \\
\hline Student 33 & 370 & 0.361 & 0.0335 & 30594.95 & \\
\hline Student 34 & 125 & 0.404 & 0.026 & 11900.23 & \\
\hline Video $=$ & 89358.83 & PowerPoint= & 101054.67 & 94371.33 & MEAN \\
\hline \multirow[t]{2}{*}{ Improvement= } & 1.14076 & & & & \\
\hline & \multicolumn{4}{|c|}{ 14\% Improvement } & \\
\hline \multirow[t]{2}{*}{ Video $=$} & 1.080169 & PowerPoint= & 1.2215482 & & \\
\hline & \multicolumn{2}{|c|}{$8 \%$ Improvement } & \multicolumn{3}{|c|}{$22 \%$ Improvement } \\
\hline
\end{tabular}

Table 2, class data after Power Point and video viewing. $\quad$ Mean: 94,371psi 
- Represented mean scores are higher with the intervention of the available teaching aids. Final psi increased over 10,000 with the addition of the Power Point tutorial and video instructional aids. At this time the recorded data is not statistically significant, from the collected data we hypothesis that the media used as a teaching and intervention tool was effective though from the $14 \%$ increase in performance. Multiple video formats have not been evaluated at this time. Student comments are being collected and evaluated for key revisions of elements related to the media.

\section{Discussion}

From the Instructor: It was definitely worth creating the media! It is one more component supporting the class that does not detract from instructional time, and can be used in various situations outside the class content. In a curriculum with multiple labs, this is very important. You can't get 15 students up next to that machine at one time. A video of a basic skill like this can be used as an introductory interaction and allow the instructor to work with other students concurrently. "More Advanced systems of communication will come into operation, opening up new strategies for the teacher, relieving him of the time consuming petty tasks which at present keep him over preoccupied. Fingertip control over the groundwork routines will ensure higher all around standards of instruction and higher levels of attainment." Educational technology is not a new idea, video is not a cutting edge method of delivery, using it to foster higher levels of learning, coupled with embedded online and lab based content many also not be new. Managing this process in an effective manner is more the intent, or a beginner's guide to embedded video instruction.

Further, the video is being used to support discussions of metallurgical evolution and property characterization and prediction. The instructor is convinced that class time spent with appropriate material, reaching multiple levels of student learning, pays off in regards to time used making the material. In addition it is available for subsequent classes and available for other departmental needs.

Video for Operations: We do not have a specific program requirement for demonstrating an ability to repair band saw blades. However, this scenario does occur, so it's incumbent for us to address it. It's a bonus that it serves as an example for our resistance-welding outcome.

Educational Value: We consider the video effective simply due to the positive survey response of the students (100\% of the students liked it). Additional metrics (e.g. tests) compiled include data results form both quarters of class. All students in the winter quarter viewed the video either in class or via Blackboard.

To Do: A future endeavor is envisioned to assess if multiple videos would provide better results. In other words, we envision a class starting with a lecture/slide mode and a short procedural video followed by students making welds. After getting weld samples, a longer video may provide more depth of understanding the results of their efforts including testing procedures for students to individually obtain the optimal process on their own. Resultant of these discoveries and analysis students will construct a premium sample and synthesis the learning process in context to other applications. 
In the continuation of this project we will used Blackboard to track the student's use of video 'views'. We can track when the students (and how many) viewed the videos. This information will be useful in future classes and help in the evaluation of effectiveness of such teaching aids. Currently through our informal evaluation of the data presented, having the PowerPoint format available for students to print or post at the work station is an effective teaching tool.

Additionally one can conclude the use of the video in addition to lecture and static diagrams has improved the end result of increasing the student's ability to make an effective resistance weld in the repair of a band saw blade. Students not only increased the effectiveness of this task, demonstrating their ability to perform the weld, 'applying,' (see Figure 1) but also transferred how they learned to a personal assignment. In the synthesis of the student's personal assignment, "creating," a procedural teaching aid, higher levels of cognitive skills were needed. These additional learning levels require students to, "remember," the knowledge required for a chosen task, "understand and apply" the knowledge to course content, "analyze and organize," ways to present the material, and "evaluate and reflect," its effectiveness on their peer group, and finally, "create," (see Figure 2) and modify their content.

\section{Conclusion}

This video and digital media creation was a success. Students performed well using the video, and it provided extra instructional time for the class. The video was thought useful by the students. Video segments coupled with Power Point will be investigated for further study. The positive impact of this video was demonstrated by student improvement via tests and performance assessment.

A specific result of interest was the positive aspect of viewing the video after trying to make the weld, and the resulting increase in the ability of students to alter the weld process under varying conditions.

Student created media required by student projects is a springboard to effectively increasing the potential of the instructor, students and program.

\section{Acknowledgements}

Thanks to Bill Cattin for his expertise. Also, thanks to the students of the class for using the videos and providing feedback for this project.

\section{Bibliography}

1. Bloom, B.S., "Taxonomy of Educational Objectives: The Classification of Educational Goals", P201 1956.

2. 'Manufacturing Education Videos', Georgia Tech, www.ndsl.org, 2009

3. Churches, A, "Blooms Digital Taxonomy",

http://edorigami.wikispaces.com/file/view/bloom\%27s+Digital+taxonomy+v3.01.pdf, March 6, 2011.

4. APmachinist, http://www.youtube.com/watch?v=zHhDXifoZmA April 10, 2010. 
5. http://thinkexist.com/quotes/william_arthur_ward/, March 6, 2011

6. Kent, Graime "From Blackboard to Computer", Ward Lock Ed., P7, 1969

7. http://www.brainyquote.com/quotes/keywords/understand.html, March 6, 2011

8. Richmond, Kenneth W., "Teachers and Machines”, Collins, 1965 